JINOTEP Vol 8 (3) (2021): 194-206

DOI: 10.17977/um031v8i22021p194

JINOTEP (Jurnal Inovasi Teknologi Pembelajaran)

Kajian dan Riset Dalam Teknologi Pembelajaran

http://journal2.um.ac.id/index.php/jinotep/index

\title{
ANALISIS FAKTOR-FAKTOR KESUKSESAN E-LEARNING DALAM MENINGKATKAN KUALITAS BELAJAR MENGAJAR DI UNIVERSITAS TELKOM
}

\author{
Fetty Poerwita Sary, Adhi Prasetio, Milleniartha Moslem
}

Fakultas Ekonomi dan Bisnis, Universitas Telkom, Bandung

\section{Article History \\ Received: 02-06-2021 \\ Accepted: 11-07-2021}

Published: 16-07-2021

\section{Keywords}

E-Learning; Budaya Belajar; Efikasi Diri; Penggunaan Sistem; Kepuasan Pengguna

\begin{abstract}
Abstrak
Dalam rangka mengantisipasi fenomena belajar daring yang terus berkembang, Universitas Telkom melakukan uji coba kuliah secara blended learning. Hal tersebut penting dilakukan untuk meningkatkan kesuksesan implementasi $e$ learning. Penelitian ini bertujuan untuk mengetahui Faktor-faktor apa sajakah yang mempengaruhi kesuksesan implementasi e-learning. Sampel pada penelitian ini adalah 88 orang mahasiswa yang mengambil mata kuliah E-Commerce dan Data Management yang merupakan mata kuliah uji coba blended learning berbasis platform e-learning CELOE di Fakultas Ekonomi dan Bisnis Universitas Telkom. Alat pengumpulan data berupa kuesioner disebarkan secara online dan kemudian diolah menggunakan teknik analisis PLS-SEM. Hasil penelitian ini menunjukkan bahwa kualitas sistem berpengaruh terhadap penggunaan sistem e-learning, namun tidak berpengaruh terhadap kepuasan pemakai, kualitas informasi berpengaruh terhadap penggunaan sistem dan kepuasan pemakai, efikasi diri berpengaruh terhadap penggunaan sistem, namun tidak berpengaruh terhadap kepuasan pemakai, efikasi diri berpengaruh terhadap budaya belajar, namun tidak berpengaruh terhadap kesuksesan e-learning, penggunaan sistem berpengaruh terhadap kepuasan pemakai, dan kesuksesan e-learning, kepuasan pemakai berpengaruh terhadap kesuksesan e-learning, budaya belajar berpengaruh terhadap kepuasan pemakai dan budaya belajar berpengaruh sedang terhadap kesuksesan e-learning. Hasil-hasil penelitian tersebut menunjukkan bahwa faktor-faktor kualitas sistem, kualitas informasi dan efikasi diri dapat digunakan untuk meningkatkan kesuksesan implementasi e-learning.
\end{abstract}

\begin{abstract}
To anticipate the phenomenon of online learning that continues to grow, Telkom University conducts lecture trials using blended learning. This process is important to increase the successfulness of e-learning implementation. This study aims to investigate what factors influence the successful implementation of elearning. The sample in this study were 88 students who took the E-Commerce and Data Management courses which are the trial courses for blended learning based on the CELOE e-learning platform at the Faculty of Economics and Business, Telkom University. Data collection tools are questionnaires distributed online and then processed using the PLS-SEM analysis technique. The results of this study indicate that the quality of the system affects the use of the E-Learning system, but has no effect on user satisfaction, the quality of information affects the use of the system and user satisfaction, self-efficacy affects the use of the
\end{abstract}


system, but does not affect user satisfaction, self-efficacy affects the learning culture, but does not affect the success of e-learning, the use of the system affects user satisfaction, and the success of e-learning, user satisfaction affects the success of e-learning, learning culture affects user satisfaction and learning culture has a moderate effect on the success of e-learning. The results of this study indicate that the system quality, information quality and self-efficacy factors can be used to increase the success of e-learning implementation.

Corresponding author : Fetty Poerwita Sary

Address: Jl. Telekomunikasi No.1 Terusan Buahbatu, Bandung, Jawa Barat 40257

Instansi: Universitas Telkom

E-mail:fettyps@telkomuniversity.ac.id
2021 Universitas Negeri Malang p-ISSN 2406-8780 e-ISSN 2654-7953

\section{PENDAHULUAN}

Fenomena pembelajaran daring saat ini merupakan salah satu alternatif metode pembelajaran yang dapat diberikan kepada mahasiswa. Hal ini sejalan dengan karakteristik belajar generasi milenial atau generasi $\mathrm{Z}$ menurut survei harian Washington Post (Suganda, 2018). Dimana menurut hasil survei tersebut, terdapat beberapa karakteristik yang dimiliki oleh generasi milenial salah satunya yaitu mudah terdistraksi ketika mengerjakan sesuatu sehingga fokusnya mudah teralihkan. Generasi Z kurang memiliki perhatian ketika mengerjakan sesuatu akibat cepatnya perubahan informasi yang harus mereka proses (Schwieger \& Ladwig, 2018).

Guna mendukung karakteristik belajar generasi $\mathrm{Z}$ yang merupakan karakteristik mahasiswa saat ini, maka kita dapat menggunakan penerapan Teknologi Informasi dan Komunikasi (TIK) dalam dunia pendidikan di Indonesia saat ini, yaitu dengan mengimplementasikan program E-Learning. Menurut Tafiardi (2005). E-Learning adalah suatu model pembelajaran dalam format digital yang dikembangkan melalui perangkat elektronik.

Kehadiran internet yang semakin cepat juga memungkinkan dilakukannya pembelajaran jarak jauh (E-Learning) baik secara synchronous (real time) maupun asynchronous. Meskipun memiliki beberapa kendala seperti kendala teknis maupun sikap pasif dari peserta (Juliana et al., 2021), namun berdasarkan observasi sementara, bahwa pembelajaran yang memanfaatkan TIK dapat memudahkan proses pembelajaran kedua belah pihak baik dosen maupun mahasiswa, dapat meningkatkan motivasi belajar, serta diharapkan dapat meningkatkan prestasi. Hal ini dikarenakan $E$ Learning menuntut mahasiswa untuk bisa belajar secara mandiri, mengakses materi kuliah, berkomunikasi dalam forum diskusi dengan dosen, mengerjakan latihan soal, serta berinteraksi dengan sesama mahasiswa dalam menyelesaikan tugas-tugas kuliah.

Era pandemi Covid-19 ini telah memaksa semua universitas untuk melakukan sistem pembelajaran secara jarak jauh. Universitas Telkom masih berbenah untuk dapat menerapkan pendidikan jarak jauh secara sukses dan dapat dinikmati semua pihak yaitu dosen, mahasiswa, tenaga administrasi, orang tua, industri, dan stakeholder terkait.

Saat ini, Universitas Telkom sudah memiliki Center for E-Learning and Open Education atau yang dikenal dengan CELOE. CELOE merupakan platform penunjang pembelajaran daring dan ekosistem baru dalam pengembangan pembelajaran di Universitas Telkom. CELOE diluncurkan pada tahun 2018 jauh sebelum pandemi adanya Covid-19. CELOE digunakan bagi mahasiswa program reguler dan pendidikan jarak jauh (PJJ) untuk mengakses kebutuhan akademis mulai dari online class dan online course.

Meskipun sudah diluncurkan dari 2018, namun penggunaan CELOE secara massal baru dilakukan pada 2020. Tepatnya pada bulan Maret ketika diputuskan bahwa perkuliahan dilaksanakan secara online. Tentu saja hal ini menimbulkan beberapa kendala yang dihadapi. Baik dari segi fasilitas, kesiapan sistem maupun materi.

Sementara itu, berdasarkan hasil observasi dan wawancara dengan dosen pengampu, masih ditemukan kendala dalam penerapan $E$ Learning ini pada mata kuliah E-Commerce. 
196 JINOTEP (Jurnal Inovasi dan Teknologi Pembelajaran) Kajian dan Riset dalam Teknologi Pembelajaran Vol.8, No.2, July 2021, Hal. 194-206

Perbaikan ini dilakukan secara terus menerus untuk menyiapkan kesiapan sistem dan materi E-learning dan demi kesuksesan implementasi kurikulum 2020/2021. Mata kuliah ECommerce dipilih karena merupakan mata kuliah yang sudah menjadi objek uji coba penerapan blended learning sebelum perkuliahan online akibat Covid-19.

\section{Teori dan hipotesis}

Teori E-Learning adalah pemanfaatan teknologi komputer, jaringan, dan internet dalam proses pembelajaran jarak jauh (distance learning) (Hamdani, 2011). Menurut Seliana et al. (2020) E-Learning juga dapat kita sebut belajar yang menggunakan akses internet dalam prosesnya atau disebut web-based learning. Penerapan E-Learning dalam pendidikan merupakan pendekatan inovatif pada peserta didik yang bersifat interaktif dan fleksibel dengan memanfaatkan teknologi digital (Maudiarti, 2018).

DeLone dan McLean dalam Jogiyanto (2008) dalam penelitiannya menyebut dengan istilah manfaat bersih (net benefit) atau kesuksesan E-Learning untuk merujuk pada semua manfaat pembelajaran yang menggunakan sistem E-Learning. Dimana, ketika E-Learning dirasa oleh penggunanya dapat memberikan banyak keuntungan yang memudahkan mereka untuk mendapatkan materi, memahami materi yang mereka dapatkan sehingga mampu meningkatkan prestasi dan hasil belajar mereka, maka pada saat itulah sistem pembelajaran E-Learning dianggap sukses.

Delone dan McLean dalam (Jogiyanto, 2008) juga mengembangkan suatu model yang disebut dengan D \& M IS Success Model (model kesuksesan sistem informasi DeLone \& McLean). Model ini mengukur kesuksesan sistem informasi dari enam elemen yaitu kualitas sistem, kualitas informasi, kualitas pelayanan, penggunaan, kepuasaan pengguna, dan manfaat-manfaat bersih.

Teori kualitas sistem menurut (Jogiyanto, 2008) menjelaskan bahwa "kualitas sistem digunakan untuk mengukur kualitas sistem teknologi itu sendiri". Selain itu menurut Ong et al. (2009) kualitas informasi dapat diartikan pengukuran kualitas konten dan dari sistem informasi. Kualitas sistem merupakan karakteristik keberhasilan dari suatu sistem informasi yang diterapkan mencakup software dan hardware (Seliana et al., 2020). Dari penjabaran diatas maka dapat disimpulkan bahwa sistem teknologi yang berkualitas merupakan interaksi yang baik antara pengguna dan sistem itu sendiri yaitu antara keluaran atau informasi yang diproduksi oleh sistem, serta nilai manfaat yang dirasakan oleh pengguna. Beberapa penelitian menunjukkan bahwa kualitas sistem memiliki pengaruh terhadap kepuasan pengguna dan penggunaan sistem (Aldholay et al., 2018; Kurt, 2019). Kualitas informasi juga ditemukan memiliki pengaruh terhadap penggunaan sistem (Aldholay et al., 2018) dan kepuasan pengguna (Aldholay et al., 2018; Kurt, 2019).

Teori kepuasan pengguna menurut Jogiyanto (2008) adalah "respon pemakai terhadap penggunaan keluaran sistem Informasi". Sedangkan menurut Seliana et al. (2020) kepuasan pengguna merupakan nilai yang diberikan atas perasaan pengguna sistem informasi. Doll dan Torkzadeh (1998) mendefinisikan End-User Satisfaction (EUS) sebagai sikap afektif seseorang akibat dari interaksi orang tersebut terhadap aplikasi perangkat lunak tertentu sehingga munculah kepuasan yang dirasakan oleh pengguna selama mengoperasikan sistem tersebut dengan komputer. Kepuasan ini muncul karena pengguna merasa bahwa sistem yang digunakan dapat dimanfaatkan secara optimal Ketika berinteraksi langsung dengan sistem tersebut. Oleh karena itu, dapat disimpulkan bahwa kepuasan pengguna adalah tanggapan atau perilaku pengguna ketika berinteraksi dengan sistem sehingga luaran dari sistem dapat dioptimalkan. Beberapa penelitian menunjukkan bahwa penggunaan sistem berpengaruh signifikan terhadap kepuasan pengguna (Aldholay et al., 2018; Isaac et al., 2017; Ramirez-Correa et al., 2017). Penelitian lain menunjukkan bahwa kualitas informasi dan kualitas sistem berpengaruh terhadap kepuasan pengguna (Cidral et al., 2018).

Teori kesuksesan penggunaan sistem merujuk pada bagaimana dan seberapa mudah sistem informasi ini digunakan oleh penggunanya. Konsep mengukur penggunaan sistem ini dapat dilihat dari berbagai perspektif. Dalam hal ini, kesuksesan lebih merujuk pada penggunaan sistem secara sukarela, dimana pengguna tidak merasa dipaksa untuk mengakses sistem tersebut, tapi justru karena merasa membutuhkan. Penelitian menunjukkan 
bahwa kesuksesan sistem dipengaruhi oleh penggunaan sistem dan kepuasan pengguna (Cidral et al., 2018; Estriegana et al., 2019; Kurt, 2019). Namun demikian, penelitian lain yang dilakukan di Maroko menemukan bahwa kepuasan pengguna tidak berpengaruh secara langsung terhadap kesuksesan sistem (Safsouf et al., 2020).

Teori efikasi diri adalah kepercayaan diri seseorang bahwa dia memiliki kemampuan untuk mengendalikan diri mereka terhadap kejadian yang ada disekitar mereka. Bandura dalam Feist dan Gregory (2006). Menurut Wood dan Bandura (1989) efikasi diri adalah kemampuan seseorang untuk memotivasi dirinya sendiri, memberdayakan sumber kognitif yang dimilikinya, dan melakukan serangkaian tindakan yang diperlukan untuk menghadapi situasi tertentu. Efikasi diri merupakan bagian dari kepercayaan diri seseorang dalam menggunakan teknologi $E$ Learning (Ithriah et al., 2020). Beberapa penelitian menunjukkan bahwa efikasi diri memiliki pengaruh terhadap kepuasan pengguna (Liaw \& Huang, 2013; Saied, 2017; Wei \& Chou, 2020) dan penggunaan sistem (Aldholay et al., 2018).

Teori budaya belajar merupakan kebiasaan belajar siswa yang terbentuk atas serangkaian kegiatan dalam melaksanakan tugas belajar. Segala bentuk perilaku baik yang terjadi dalam proses pembelajaran harus selalu ditingkatkan agar menjadi kebiasaan yang baik di kemudian hari. Jadi, budaya belajar yang baik yaitu jika dalam kebiasaan tersebut misalnya konsisten menerapkan cara belajar yang efektif, teratur dalam menyelesaikan tugas, memiliki daya fokus dan manajemen waktu yang baik, disiplin, gigih dan ulet, serta memiliki keunggulan kompetitif.

Berdasarkan fenomena diatas, peneliti tertarik untuk melakukan sebuah penelitian untuk mengungkap "Faktor-faktor kesuksesan E-Learning dalam Meningkatkan Kualitas Belajar Mengajar di Universitas Telkom Bandung".

Hipotesis dalam penelitian ini adalah sebagaimana terlihat pada gambar 1 .

Adapun permasalahan yang akan dibahas di dalam penelitian ini meliputi hal-hal berikut:

1. Bagaimana Kualitas sistem E-Learning di Universitas Telkom?
2. Bagaimana Kualitas Informasi E-Learning di Universitas Telkom?

3. Bagaimana Efikasi Diri Mahasiswa di Universitas Telkom?

4. Bagaimana Penggunaan Sistem E-Learning di Universitas Telkom?

5. Bagaimana Kepuasan pengguna $E$ Learning di Universitas Telkom?

6. Bagaimana Budaya Belajar E-Learning di Universitas Telkom?

7. Bagaimana Kesuksesan E-Learning di Universitas Telkom?

8. Bagaimana pengaruh Kualitas Sistem terhadap Penggunaan Sistem E-Learning?

9. Bagaimana pengaruh Kualitas Sistem terhadap Kepuasan Pengguna E-Learning?

10. Bagaimana pengaruh Kualitas Informasi terhadap Penggunaan Sistem E-Learning?

11. Bagaimana pengaruh Kualitas Informasi terhadap Kepuasan Pengguna E-Learning?

12. Bagaimana Pengaruh Efikasi diri terhadap Penggunaan sistem E-Learning?

13. Bagaimana Pengaruh Efikasi diri terhadap Kepuasan pengguna E-Learning?

14. Bagaimana Pengaruh Efikasi diri terhadap Budaya Belajar E-Learning?

15. Bagaimana Pengaruh Efikasi diri terhadap Kesuksesan E-Learning?

16. Bagaimana Pengaruh Penggunaan Sistem terhadap Kepuasan E-Learning?

17. Bagaimana Pengaruh Penggunaan Sistem terhadap Kesuksesan E-Learning?

18. Bagaimana Pengaruh Budaya Belajar terhadap Kepuasan Pengguna E-Learning?

19. Bagaimana Pengaruh Budaya Belajar terhadap Kesuksesan E-Learning?

20. Bagaimana Pengaruh Kepuasan Pengguna terhadap Manfaat E-Learning?

Penelitian ini bertujuan untuk mengetahui faktor-faktor apa yang mempengaruhi kesuksesan implementasi $E$ Learning terutama dengan metode blended learning yang dapat meningkatkan motivasi dan hasil belajar siswa (Aritantia et al., 2021). Hasil penelitian ini diharapkan dapat memberi masukan dan pandangan bagi implementasi $e$ learning terutama yang menggunakan metode blended learning. 
198 JINOTEP (Jurnal Inovasi dan Teknologi Pembelajaran) Kajian dan Riset dalam Teknologi Pembelajaran Vol.8, No.2, July 2021, Hal. 194-206

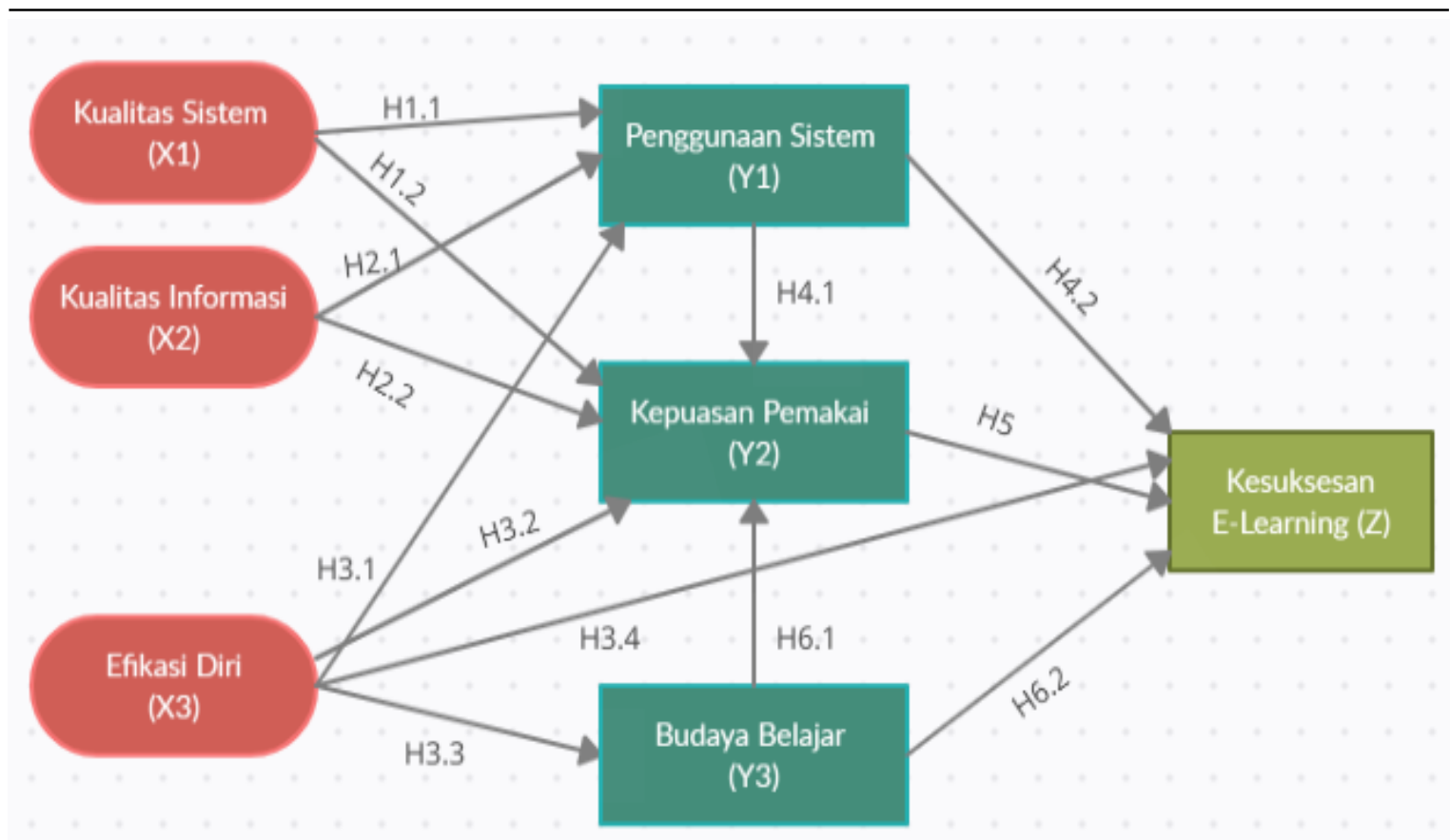

Gambar 1. Gambar Hipotesis Penelitian

\section{METODE}

Penelitian ini merupakan jenis penelitian deskriptif yaitu penelitian yang menyajikan gambaran yang lengkap tentang situasi khusus, setting sosial, atau korelasional. Sementara itu, digunakan pendekatan metode deskriptif kuantitatif yang dimaksudkan untuk melakukan eksplorasi dan klarifikasi mengenai masalah yang sedang diteliti, dengan jalan mendeskripsikan variabel yang berkenaan dengan masalah dan unit yang diteliti melalui metode kuantitatif.

Dalam penulisan ini, objek penelitian yang dipilih oleh penulis adalah Mahasiswa Prodi MBTI Fakultas Ekonomi dan Bisnis Universitas Telkom yang mengontrak mata kuliah E-Commerce dan Data Management di semester genap 2019/2020. Pemilihan obyek ini dilakukan terhadap kelas yang dapat dikontrol implementasi blended learning oleh peneliti untuk memastikan bahwa uji coba dilaksanakan sesuai rencana.

Populasi penelitian ini adalah seluruh mahasiswa Prodi MBTI yang mengambil mata kuliah E-Commerce dan Data Management yang sudah menggunakan CELOE di semester genap 2019/2020 sebanyak kurang lebih 88 orang. Teknik sampling yang digunakan yaitu dengan menggunakan sampling jenuh. Teknik pengumpulan data dengan menggunakan penelitian pustaka dan penelitian lapangan dengan menyebarkan kuesioner.

Variabel dalam penelitian ini terdiri atas variabel eksogen dan endogen. Variabel eksogen terdiri dari kualitas sistem (X1), kualitas informasi (X2) dan efikasi diri (X3) sedangkan variabel endogen yaitu penggunaan sistem (Y1), kepuasan pengguna (Y2), budaya belajar (Y3) dan kesuksesan E-Learning (Z).

Faktor-faktor kesuksesan yang akan digunakan menggunakan model dari penelitian Santoso dan Legowo (2015) yang merupakan hasil modifikasi dari penelitian sebelumnya yang dilakukan oleh Lee-Post (2009) yang berjudul E-Learning Success Model: An Information Systems Perspective. Pada penelitian Lee-Post, peneliti menggunakan model DeLone dan McLean (2003) menitikberatkan pada sistem informasinya sehingga variabel-variabel yang digunakan adalah system design yang terdiri dari kualitas sistem, kualitas informasi, dan kualitas service, kemudian system outcome yang terdiri dari manfaat dan kepuasan pengguna dengan menjadikan system delivery sebagai variabel moderating.

Sementara itu, Santoso dan Legowo, (2015) menambahkan variabel lain yaitu efikasi diri dan budaya Belajar dalam rangka mengukur juga proses belajar mengajar itu sendiri. Model ini dianggap kurang lebih sa- 
Tabel 1. Kategori Path Coefficient

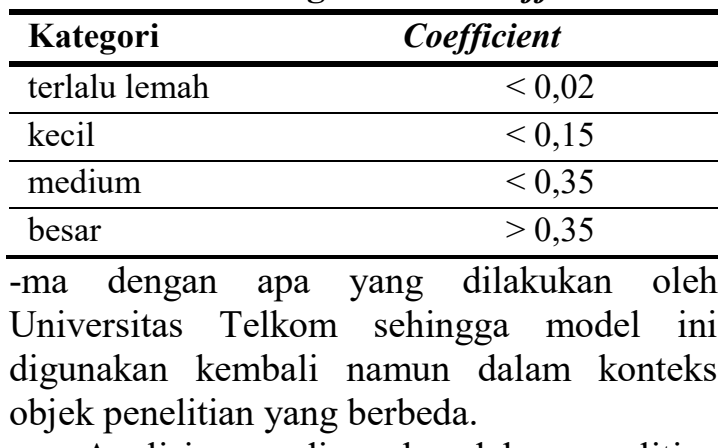

Analisis yang digunakan dalam penelitian ini adalah analisis deskriptif dan PLSStructural Equation Modeling (SEM). Adapun langkah-langkah dalam analisis PLS-SEM adalah pengujian outer model dan inner model. Uji persyaratan analisis penelitian ini dibagi menjadi tiga yaitu uji validitas, uji reliabilitas dan uji normalitas data (inner model).

Analisis Structural Equation Model (SEM) (outer model) adalah gabungan dari analisis faktor dan regresi. Pengujian model dalam SEM dilakukan dengan dua pengujian uji signifikansi kausalitas dan path koefisien. Pengujian hipotesis memiliki kriteria hipotesis diterima jika $P$ value $<0,05$. Path koefisien menunjukkan bagaimana pengaruh variabel terhadap variabel lainnya. Path coefficient ini dikelompokkan menjadi empat kategori sebagaimana pada tabel 1 (Kock, 2020).

\section{HASIL}

Hasil penelitian dibagi menjadi dua bagian. Bagian pertama yaitu deskriptif untuk melihat profil responden dan bagaimana tingkat jawaban responden terhadap masingmasing variabel laten. Bagian kedua menggunakan teknik analisis PLS-SEM untuk menguji hipotesis dan melihat bagaimana kategori pengaruh masing-masing variabel terhadap variabel lainnya.

Sebagaimana ditunjukkan pada tabel 2 profil responden yang berhasil dikumpulkan dibagi menjadi tiga bagian yaitu dilihat dari gender, mata kuliah dan kelasnya. Dari sisi gender, responden yang diperoleh hampir seimbang antara pria dan wanita. Pria sedikit lebih banyak dengan persentase $51 \%$. Mata kuliah didominasi oleh E-Commerce dengan proporsi $63 \%$, sedangkan kelas sedikit di dominasi oleh MB42-07 dengan proporsi 37\%. Kelas ini merupakan kelas reguler yang memiliki jumlah mahasiswa yang lebih banyak dibandingkan dua kelas lain yang merupakan kelas internasional.

Tabel 2. Karakteristik Deskriptif Responden

\begin{tabular}{lc}
\hline Kategori & Koefisien \\
\hline Jenis Kelamin & \\
Perempuan & $51 \%$ \\
Laki-Laki & $49 \%$ \\
\hline Mata Kuliah & \\
E-Commerce & $63 \%$ \\
Manajemen Data & $37 \%$ \\
\hline Kelas & \\
MB41-INT-1 & $30 \%$ \\
MB41-INT-2 & $33 \%$ \\
MB42-07 & $37 \%$ \\
\hline
\end{tabular}

Tabel 3. Kategori Variabel

\begin{tabular}{lccl}
\hline $\begin{array}{c}\text { Variabel } \\
\text { Laten }\end{array}$ & $\begin{array}{c}\text { Jumlah } \\
\text { Indikator }\end{array}$ & $\begin{array}{c}\text { Rata- } \\
\text { Rata }\end{array}$ & Kategori \\
\hline $\begin{array}{l}\text { Kualitas } \\
\text { Sistem }\end{array}$ & 3 & 3.0 & $\begin{array}{l}\text { Agak } \\
\text { rendah }\end{array}$ \\
\hline $\begin{array}{l}\text { Kualitas } \\
\text { Informasi }\end{array}$ & 2 & 3.1 & $\begin{array}{l}\text { Agak } \\
\text { rendah }\end{array}$ \\
\hline Efikasi Diri & 3 & 2.6 & Rendah \\
\hline $\begin{array}{l}\text { Penggunaan } \\
\text { Sistem }\end{array}$ & 3 & 1.8 & $\begin{array}{l}\text { Sangat } \\
\text { rendah }\end{array}$ \\
\hline
\end{tabular}

Hasil perhitungan rata-rata jawaban responden untuk setiap variabel laten dan kategorinya dapat dilihat pada tabel berikut ini. Secara umum, tanggapan responden terhadap variabel masuk dalam kategori agak rendah yaitu di kisaran 3 dari 7. Ini berarti bahwa tanggapan responden masih berada di bawah nilai tengah yaitu 3,5 . Terdapat dua variabel yang lebih rendah dibandingkan variabel lainnya yaitu efikasi diri dengan kategori rendah, dan penggunaan sistem dengan kategori sangat rendah.

Pengujian hipotesis dilakukan menggunakan teknik analisis PLS-SEM. Teknik analisis ini terdiri dari dua jenis analisis yaitu outer model dan inner model. Software yang digunakan adalah Warppls versi 7.0. Sebelum dilakukan pengujian hipotesis dalam inner model, langkah yang harus dilakukan terlebih dahulu adalah pengujian outer model untuk melihat bagaimana validitas dan reliabilitas indikator dalam mengukur variabel latennya. 
200 JINOTEP (Jurnal Inovasi dan Teknologi Pembelajaran) Kajian dan Riset dalam Teknologi Pembelajaran Vol.8, No.2, July 2021, Hal. 194-206

Model awal memiliki indikator lengkap. Namun demikian, pemrosesan di tahap awal menunjukkan bahwa terjadi masalah common bias method yang ditunjukkan dengan tingkat multikolinearitas yang tinggi. Untuk mengatasi masalah multikolinearitas ini, beberapa indikator yang menyebabkan masalah tersebut perlu dihapus. Setelah masalah multikolinearitas ini diatasi, analisis selanjutnya adalah analisis outer model.

Analisis outer model yang pertama adalah uji validitas. Uji validitas konvergen dapat dilihat dari nilai $\mathrm{P}$ value dan nilai loading masing-masing indikator. Model dinyatakan memenuhi validitas konvergen jika $\mathrm{P}$ value dari masing-masing indikator bernilai kurang dari 0,05 dan loading dari masing-masing faktor lebih besar dari 0,5 (Kock, 2014). Berikut adalah hasil uji validitas konvergen.

Tabel 4 menunjukkan hasil $P$ value dan nilai loading dari setiap indikator yang digunakan. Dari tabel tersebut, dapat dilihat bahwa semua $P$ value memiliki nilai di bawah 0,05 dan nilai loading di atas 0,5 . Dengan demikian, model sudah memenuhi persyaratan validitas konvergen. Pengujian outer model berikutnya yaitu validitas diskriminan kriteria yang digunakan adalah dengan melihat korelasi square root dari nilai average variance extracted (AVE). Berikut adalah hasil uji validitas diskriminan.

Tabel 4. Hasil Uji Validitas Konvergen

\begin{tabular}{ccc}
\hline Variabel & Se & P Value \\
\hline $\mathrm{X} 12$ & 0.081 & $<0.001$ \\
\hline $\mathrm{X} 15$ & 0.082 & $<0.001$ \\
\hline $\mathrm{X} 13$ & 0.081 & $<0.001$ \\
\hline $\mathrm{X} 23$ & 0.081 & $<0.001$ \\
\hline $\mathrm{X} 24$ & 0.081 & $<0.001$ \\
\hline $\mathrm{X} 32$ & 0.081 & $<0.001$ \\
\hline $\mathrm{X} 33$ & 0.081 & $<0.001$ \\
\hline $\mathrm{X} 34$ & 0.081 & $<0.001$ \\
\hline $\mathrm{Y} 11$ & 0.082 & $<0.001$ \\
\hline $\mathrm{Y} 12$ & 0.081 & $<0.001$ \\
\hline $\mathrm{Y} 13$ & 0.083 & $<0.001$ \\
\hline $\mathrm{Y} 21$ & 0.085 & $<0.001$ \\
\hline $\mathrm{Y} 23$ & 0.082 & $<0.001$ \\
\hline $\mathrm{Y} 26$ & 0.082 & $<0.001$ \\
\hline $\mathrm{Y} 31$ & 0.084 & $<0.001$ \\
\hline $\mathrm{Y} 32$ & 0.083 & $<0.001$ \\
\hline $\mathrm{Y} 33$ & 0.088 & $<0.001$ \\
\hline $\mathrm{Y} 34$ & 0.082 & $<0.001$ \\
\hline $\mathrm{Y} 35$ & 0.085 & $<0.001$ \\
\hline $\mathrm{Y} 36$ & 0.084 & $<0.001$ \\
\hline $\mathrm{Z} 11$ & 0.082 & $<0.001$ \\
\hline $\mathrm{Z} 12$ & 0.081 & $<0.001$ \\
\hline $\mathrm{Z} 16$ & 0.082 &
\end{tabular}

Tabel 5. Hasil Uji Validitas Konvergen

\begin{tabular}{cccccccc}
\hline & SQ & IQ & SE & U & US & LC & SC \\
\hline SQ & 0.934 & 0.833 & 0.709 & 0.802 & 0.773 & 0.64 & 0.658 \\
\hline IQ & 0.833 & 0.928 & 0.762 & 0.835 & 0.831 & 0.67 & 0.762 \\
\hline SE & 0.709 & 0.762 & 0.959 & 0.834 & 0.776 & 0.813 & 0.707 \\
\hline U & 0.802 & 0.835 & 0.834 & 0.906 & 0.839 & 0.766 & 0.777 \\
\hline US & 0.773 & 0.831 & 0.776 & 0.839 & 0.864 & 0.795 & 0.829 \\
\hline LC & 0.64 & 0.67 & 0.813 & 0.766 & 0.795 & 0.814 & 0.778 \\
\hline SC & 0.658 & 0.762 & 0.707 & 0.777 & 0.829 & 0.778 & 0.911 \\
\hline
\end{tabular}


*Keterangan:

$\mathrm{SQ}=$ Kualitas Sistem (System Quality)

$\mathrm{IQ}=$ Informasi Sistem (Information Quality)

$\mathrm{SE}=$ Efikasi Diri (Self Efficacy)

$\mathrm{U}=$ Penggunaan Sistem (Use)

US $=$ Kepuasan Pemakai (User Satisfaction)

$\mathrm{LC}=$ Budaya Belajar (Learning Culture)

$\mathrm{SC}=$ Kesuksesan E-Learning (System Success)

Hasil pengujian validitas diskriminan yang ditunjukkan pada tabel 5 menunjukkan bahwa model sudah memenuhi kriteria validitas diskriminan. Nilai korelasi square root $A V E$ ada pada diagonal tabel yang ditunjukkan dengan latar belakang berbeda.

Reliabilitas dalam PLS-SEM dapat dilihat dari nilai composite reliability dan cronbach's alpha. Model dinyatakan memenuhi kriteria reliabilitas jika nilai composite reliability dan cronbach's alpha lebih besar dari 0,7 (Fornell dan Larcker (1981); Nunnally dan Bernstein (1994); Kock dan Lynn (2012) dan Kock (2014). Berikut adalah hasil uji reliabilitas yang sudah dilakukan.

Tabel 6 menunjukkan bahwa kriteria reliabilitas sudah dapat dipenuhi untuk model yang digunakan dalam penelitian ini. Dapat disimpulkan bahwa model yang digunakan sudah tidak memiliki masalah multikolinearitas, dan sudah memenuhi kriteria outer model yaitu validitas konvergen, validitas diskriminan dan reliabilitas. Untuk itu, proses berikutnya yaitu analisis terhadap inner model dapat dilakukan.

Selanjutnya adalah uji inner model untuk menjawab pertanyaan penelitian tentang bagaimana pengaruh masing-masing variabel terhadap variabel lainnya. Penelitian ini menggunakan dua jenis analisis yaitu pengujian hipotesis dan pengelompokan path coefficient. Tabel 7 adalah hasil path coefficient.

Tabel 6. Hasil Uji Reabilitas

\begin{tabular}{lcc}
\hline \multicolumn{2}{c}{ Reliabilitas } \\
\hline & $\begin{array}{c}\text { Composite } \\
\text { Reliability } \\
\text { Coefficients }\end{array}$ & $\begin{array}{c}\text { Cronbach's Alpha } \\
\text { Coefficients }\end{array}$ \\
\hline SQ & 0.954 & 0.927 \\
\hline IQ & 0.925 & 0.839 \\
\hline SE & 0.971 & 0.958 \\
\hline U & 0.932 & 0.89 \\
\hline US & 0.898 & 0.828 \\
\hline LC & 0.921 & 0.896 \\
\hline SC & 0.936 & 0.897 \\
\hline
\end{tabular}

Tabel 7. Nilai $P$ Value Pengaruh Variabel

\begin{tabular}{ccccccc}
\hline & SQ & IQ & SE & U & US & LC \\
\hline $\mathrm{U}$ & $\begin{array}{c}0.01 \\
4\end{array}$ & $\begin{array}{c}<.00 \\
1\end{array}$ & $\begin{array}{c}<0.00 \\
1\end{array}$ & & & \\
\hline $\mathrm{U}$ & $\begin{array}{c}4.27 \\
9\end{array}$ & $\begin{array}{c}<.00 \\
\mathrm{~S}\end{array}$ & 0.238 & $\begin{array}{c}0.00 \\
3\end{array}$ & & $<0.00$ \\
1 & & 3 & & 1 \\
\hline $\mathrm{L}$ & \multicolumn{7}{c}{$<0.00$} & & & \\
$\mathrm{C}$ & & & 1 & & & \\
\hline $\mathrm{S}$ & & & 0.060 & 0.01 & $<0.00$ & $<0.00$ \\
$\mathrm{C}$ & & & & 8 & 1 & 1 \\
\hline
\end{tabular}

Tabel 8. Hasil Path Coefficient

\begin{tabular}{|c|c|c|c|c|c|c|}
\hline & SQ & IQ & SE & $\mathbf{U}$ & US & LC \\
\hline $\bar{U}$ & $\begin{array}{l}0.22 \\
2\end{array}$ & $\begin{array}{l}0.34 \\
8\end{array}$ & $\begin{array}{l}0.39 \\
1\end{array}$ & & & \\
\hline $\mathrm{U}$ & 0.06 & 0.49 & 0.07 & 0.27 & & 0.31 \\
\hline S & 2 & 8 & 5 & 8 & & 8 \\
\hline $\begin{array}{l}\mathrm{L} \\
\mathrm{C}\end{array}$ & & & $\begin{array}{l}0.82 \\
7\end{array}$ & & & \\
\hline $\bar{S}$ & & & 0.16 & 0.21 & 0.52 & 0.31 \\
\hline $\mathrm{C}$ & & & 0 & 3 & 4 & 6 \\
\hline
\end{tabular}

Tabel 9. Hasil Kategori Path Coefficient

\begin{tabular}{|c|c|c|c|c|c|c|}
\hline & SQ & IQ & SE & $\mathbf{U}$ & US & $\mathbf{L C}$ \\
\hline $\mathrm{U}$ & Med. & Med. & Bs. & & & \\
\hline US & Kc. & Bs. & Kc. & Med. & & Med. \\
\hline $\mathrm{LC}$ & & & Bs. & & & \\
\hline $\mathrm{SC}$ & & & Med. & Med. & Bs. & Med. \\
\hline
\end{tabular}

*Keterangan:

Bs. $=$ Besar

Med. $=$ Medium

Kc. $=$ Kecil

Hasil keseluruhan dari analisis inner model dapat dilihat pada tabel 9. Dari tabel tersebut dapat dilihat bahwa terdapat tiga hipotesis yang ditolak yaitu pengaruh kualitas sistem terhadap kepuasan pemakai, pengaruh efikasi diri terhadap kepuasan pemakai dan pengaruh efikasi diri terhadap kesuksesan E-Learning. Pengelompokan pengaruh masing-masing variabel pada tabel 10 menunjukkan bahwa terdapat empat variabel yang memiliki pengaruh besar, tujuh variabel yang memiliki pengaruh medium, dan dua variabel yang memiliki pengaruh kecil.

Berdasarkan penjabaran dari hasil penghitungan PLS-SEM pada tabel 10, maka dapat disimpulkan bahwa dari tujuh variabel yang diteliti yaitu kualitas sistem, kualitas informasi, efikasi diri, penggunaan sistem $E$ Learning, kepuasan pengguna E-Learning, Budaya belajar dengan menggunakan $E$ Learning, dan kesuksesan E-Learning maka efikasi diri dan penggunaan sistem E-Learning berada pada kategori rendah dan sangat rendah. 
202 JINOTEP (Jurnal Inovasi dan Teknologi Pembelajaran) Kajian dan Riset dalam Teknologi Pembelajaran Vol.8, No.2, July 2021, Hal. 194-206

Tabel 10. Hasil Pengujian Hipotesis dan Pengelompokan Path Coefficient

\begin{tabular}{llc}
\hline \multicolumn{1}{c}{ Hipotesis } & Hasil Uji & Kategori Path Coefficient \\
\hline H1.1 Kualitas sistem --> Penggunaan sistem & Diterima & Medium \\
\hline H1.2 Kualitas sistem --> Kepuasan pemakai & Ditolak & Kecil \\
\hline H2.1 Kualitas informasi --> Penggunaan sistem & Diterima & Medium \\
\hline H2.2 Kualitas informasi --> Kepuasan pemakai & Diterima & Besar \\
\hline H3.1 Efikasi diri --> Penggunaan sistem & Diterima & Besar \\
\hline H3.2 Efikasi diri --> Kepuasan pemakai & Ditolak & Kecil \\
\hline H3.3 Efikasi diri --> Budaya belajar & Diterima & Besar \\
\hline H3.4 Efikasi diri --> Kesuksesan E-Learning & Ditolak & Medium \\
\hline H4.1 Penggunaan sistem --> Kepuasan pemakai & Diterima & Medium \\
\hline H4.2 Penggunaan sistem --> Kesuksesan E-Learning & Diterima & Medium \\
\hline H5 Kepuasan pemakai --> Kesuksesan E-Learning & Diterima & Besar \\
\hline H6.1 Budaya belajar --> Kepuasan pemakai & Diterima & Medium \\
\hline H6.2 Budaya belajar --> Kesuksesan E-Learning & Diterima & Medium \\
\hline
\end{tabular}

\section{PEMBAHASAN}

Hasil penelitian menunjukkan bahwa kualitas sistem mempengaruhi penggunaan sistem. Hasil ini sejalan dengan temuan pada penelitian sebelumnya (Aldholay et al., 2018; Kurt, 2019). Kedua penelitian tersebut dilakukan pada sistem e-learning di dua negara yang berbeda yaitu Yaman dan Italia. Mengingat perbedaan karakteristik e-learning pada kedua negara tersebut, maka pengaruh kualitas sistem terhadap penggunaan ini bersifat cukup umum dan dapat menjelaskan mengapa terjadi juga dalam hasil penelitian ini.

Di sisi lain, kualitas sistem ternyata tidak berpengaruh terhadap kepuasan pemakai dan efikasi diri terhadap kepuasan pemakai ternyata tidak memiliki pengaruh. Hal ini dikarenakan mahasiswa lebih merasa puas dan percaya belajar langsung dengan dosen pengampunya dibandingkan dengan menggunakan sistem $E$ Learning. Hal ini juga didukung oleh penelitian Hernita et al. (2020) dimana kualitas sistem tidak memiliki pengaruh terhadap kepuasan pemakai. Penelitian lain yang sejalan adalah penelitian oleh Yuliantoro (2015) yang menyatakan bahwa meskipun sistem $E$ Learning memudahkan pengguna dalam proses pembelajaran dan mendorong pengguna untuk menggunakannya, tapi belajar langsung dengan dosen pengajar, mahasiswa dapat langsung bertanya ketika ada yang dirasa kurang jelas. Tidak ada proses tunda dibandingkan jika menggunakan sistem E-Learning. Sehingga mahasiswa merasa lebih puas dan percaya diri menguasai materi kuliah jika belajar langsung dengan dosen. Kualitas sistem yang masih mengalami banyak kendala juga dapat menjadi penyebab hasil ini.

Berbeda dengan kualitas sistem, kualitas informasi terbukti memiliki pengaruh terhadap kepuasan pemakai. Hasil ini mendukung beberapa penelitian terdahulu (Aldholay et al., 2018; Chopra et al., 2019; Kurt, 2019). Kualitas informasi yang tersedia sudah dipersepsi sedikit lebih baik dibandingkan kualitas sistem. Berbeda dengan kualitas sistem, ketersediaan informasi yang cukup membuat peserta dapat menilai secara lebih bervariasi kualitas informasi yang sudah disediakan untuk dapat menunjukkan adanya pengaruh dari kualitas informasi terhadap kepuasan pemakai.

Efikasi diri seperti yang sudah dijelaskan pada kajian teori adalah keyakinan bahwa seseorang bisa menguasai situasi dan mendapatkan hasil positif (Wood dan Bandura (1989). Efikasi diri berpengaruh terhadap perilaku seseorang (Aldholay et al., 2018). Efikasi diri merupakan suatu keyakinan yang dimiliki seseorang bahwa dirinya memiliki kemampuan melakukan tindakan yang diharapkan. Seseorang dengan efikasi diri yang tinggi, yakin bahwa mereka mampu melakukan sesuatu yang di sekitarnya, sedangkan seseorang dengan efikasi diri rendah justru sebaliknya. Dalam situasi yang sulit, orang dengan efikasi yang rendah cenderung mudah menyerah.

Dalam konteks E-Learning, dimana hal ini merupakan hal yang baru, tentu saja hal ini berkaitan dengan kepercayaan diri mahasiswa untuk dapat menggunakan bagian dari CELOE yaitu Learning Management System (LMS) dengan baik. Hal ini memang berkaitan juga dengan variabel penggunaan Sistem E-Learning 
yang berada pada kategori sangat rendah. Hal ini menunjukkan bahwa belajar dengan menggunakan LMS merupakan hal yang baru bagi mahasiswa, mereka belum merasa nyaman dan terbiasa dalam menggunakan LMS. Belum lagi rasa percaya diri bahwa mereka bisa memahami materi melalui media pembelajaran yang diberikan oleh dosen hanya dengan menonton video yang ada di LMS atau link URL yang diberikan oleh dosen. Menurut Daar dan Nasar (2021) penting bagi pengajar untuk memperhatikan media pembelajaran yang digunakan karena media pembelajaran merupakan sarana penyampaian informasi yang akan diterima oleh mahasiswa. Jadi dapat disimpulkan masih banyak mahasiswa yang memiliki kepercayaan diri lebih baik jika belajar langsung dengan dosen yang mengampu mata kuliah tersebut.

Sementara lima variabel lainnya yaitu kualitas sistem, kualitas informasi, kepuasan, budaya, dan kesuksesan berada di kategori agak rendah, menunjukkan bahwa lima variabel ini masih perlu ditingkatkan lagi. Hal ini memang sangat mungkin terjadi, karena penelitian ini dilakukan pada saat masih uji coba LMS sehingga masih uji coba sistem. Masih banyak kekurangan pada sistem yang masih perlu untuk diperbaiki dan disempurnakan. Berkaitan dengan budaya, hal ini dikarenakan memang budaya belajar menggunakan E-Learning memang masih belum terbentuk karena $E$ Learning masih hal yang baru dan tentu saja membutuhkan proses untuk menjadikan belajar menggunakan E-Learning sebagai budaya belajar yang baru.

Jika kualitas sistem dipersepsi rendah oleh sebagian besar mahasiswa, maka variabel ini tidak akan berpengaruh pada variabel lain. Kondisi ini terjadi karena kuesioner disebarkan pada mahasiswa yang melakukan uji coba terhadap sistem kemudian mengalami beberapa kendala. Kendala yang terjadi saat sistem masih dalam masa uji coba ini seperti kesulitan untuk enroll dan login, video yang tidak bisa diputar, dan lain-lain.

Efikasi diri juga tidak memiliki pengaruh terhadap kesuksesan E-Learning, sebagaimana yang sudah dijelaskan diatas bahwa mahasiswa masih merasa lebih nyaman belajar secara langsung dengan dosen. Masih banyak yang harus dibenahi dalam E-Learning itu sendiri agar sukses yaitu bagaimana mahasiswa memiliki pengalaman belajar yang kurang lebih sama dengan yang diperolehnya jika belajar langsung dengan dosen pengampu. Hal ini juga didukung oleh penelitian yang dilakukan oleh Dewi dan Zaky (2020) di Universitas Brawijaya bahwa efikasi diri tidak berpengaruh terhadap keinginan mahasiswa untuk menggunakan $E$ Learning, penelitian tersebut menunjukan bahwa mahasiswa belum mampu mengaplikasikan E-Learning dalam proses belajar.

Sementara itu, kualitas informasi berpengaruh terhadap kepuasan pemakai. Temuan ini sejalan dengan hasil penelitian terdahulu (Aldholay et al., 2018; Kurt, 2019; Nawaz, 2019). Hal ini dikarenakan informasi yang terdapat baik di dalam sistem maupun helpdesk di luar sistem sangat diperlukan dalam mengarahkan mahasiswa ketika sedang menggunakan sistem E-Learning. Apabila pengguna sudah mahir dalam menggunakan sistem E-Learning, tentu saja akan meningkatkan kepuasan pengguna E-Learning.

Efikasi diri juga memiliki pengaruh yang besar terhadap penggunaan sistem. Temuan ini sejalan dengan temuan pada penelitian (Aldholay et al., 2018) yang artinya semakin besar kepercayaan mahasiswa bahwa dia mampu dan bisa menggunakan sistem $E$ Learning, menunjukkan bahwa mahasiswa akan semakin percaya diri dalam menggunakan $E$ Learning dan akan mau menggunakan sistem $E$ Learning seterusnya, karena telah memberikan kemudahan bagi mereka dalam belajar. Pengaruh penggunaan sistem terhadap kesuksesan e-learning ini sejalan dengan beberapa penelitian sebelumnya (Cidral et al., 2018; Estriegana et al., 2019; Kurt, 2019; Martins et al., 2019). Temuan lain dari penelitian ini adalah bahwa penggunaan sistem berpengaruh terhadap kepuasan pemakai. Temuan ini mendukung beberapa penelitian sebelumnya yang menunjukkan hasil yang sama (Aldholay et al., 2018; Isaac et al., 2017; Ramirez-Correa et al., 2017).

Selain itu, kepuasan pemakai berpengaruh besar terhadap kesuksesan E-Learning yang sejalan dengan hasil-hasil penelitian sebelumnya (Cidral et al., 2018; Estriegana et al., 2019; Kurt, 2019). Hal ini menunjukkan bahwa semakin puas pengguna, maka pengalaman yang dirasakan juga semakin baik. Hal tersebut mendorong kesuksesan penerapan E-Learning dalam suatu organisasi. 


\section{SIMPULAN}

Hasil penelitian ini menunjukkan bahwa masih terdapat beberapa variabel yang dipersepsi rendah oleh pengguna yaitu penggunaan sistem, efikasi diri, kualitas sistem dan kualitas informasi. Selain itu, hasil penelitian ini juga membuktikan bahwa model yang ditawarkan dapat digunakan untuk meningkatkan kesuksesan e-learning terutama dengan metode blended learning. Institusi dapat meningkatkan kualitas sistem, kualitas informasi dan efikasi diri untuk meningkatkan kesuksesan e-learning melalui variabel mediasi penggunaan sistem, kepuasan pemakai dan budaya belajar.

Keterbatasan dalam penelitian ini terdapat pada jumlah responden yang masih relatif kecil. Hal ini dikarenakan sistem pada saat penelitian masih dalam tahap uji coba. Penelitian selanjutnya dapat menggunakan jumlah sampel yang lebih besar dalam kondisi operasional yang sebenarnya.

Berdasarkan hasil pengolahan data saran yang diberikan kepada Universitas Telkom adalah pertama, sistem E-Learning harus dapat lebih mudah lagi digunakan dan dioperasikan. Hal ini artinya perlu dilakukan sosialisasi terus menerus mengenai bagaimana cara menggunakan sistem E-Learning, baik dengan cara langsung maupun tidak langsung. Cara langsung misalnya dengan mengadakan workshop penggunaan sistem E-Learning. Secara tidak langsung, bisa saja dengan membuat konten tutorial langkah-langkah dalam menggunakan sistem E-Learning, dimana video tersebut dapat dimasukkan ke dalam website $E$ Learning atau Youtube.

Kedua, agar rasa percaya diri mahasiswa dapat meningkat bahwa belajar melalui $E$ Learning juga hampir sama baiknya dengan belajar secara langsung dengan dosen pengampu, maka penting diperhatikan bagaimana cara pembuatan konten dan materi ajar yang menyenangkan bagi mahasiswa sehingga materi mudah dipahami. Hal ini dapat dilakukan dengan memberikan ilmu kepada dosen pembuat konten untuk belajar metode ajar yang variasi dan menarik. Sehingga, mahasiswa akan merasa mendapat kemudahan belajar melalui E-Learning sehingga akan muncul kebiasaan, inisiatif, dan budaya belajar secara mandiri dan menyesuaikan dengan learning pace masing-masing.

\section{DAFTAR RUJUKAN}

Aldholay, A., Issac, O., Zaini, A., Abdulsalam, R., \& Al-Shibami, A. . (2018). An Extension of Delone and McLean IS Success Model with Self-Efficacy Online learning Usage In Yemen. The International Journal of Information and Learning Technology, 35(4), 285-304. https://doi.org/https://doi.org/10.1108/IJIL T-11-2017-0116

Aritantia, Y., Muslim, S., Wibowo, T. W., Rijanto, T., \& Cholik, M. (2021). Kajian Literatur Sistematis Blended Learning dalam Meningkatkan Motivasi dan Hasil Belajar Siswa SMK. Jurnal Inovasi Dan Teknologi Pembelajaran, 8(2).

Bandura, A. (1997). Self-efficacy: The exercise of control. W H Freeman/Times Books/ Henry Holt \& Co.

Chopra, G., Madan, P., Jaisingh, P., \& Bhaskar, P. (2019). Effectiveness of E-learning portal from students' perspective: A structural equation model (SEM) approach. Interactive Technology and Smart Education, 16(4).

Cidral, W. A., Oliviera, T., Di Felice, M., \& Aparicio, M. (2018). E-learning success determinants: Brazilian empirical study. Computers and Education, 122, 273-290.

Daar, G. F., \& Nasar, I. (2021). Teachers Challenges in The Learning Process During The Covid19 Pandemic in Rural Areas. Jurnal Inovasi Dan Teknologi Pembelajaran, 8(2), 186193.

DeLone, W. H., \& McLean, E. R. (2003). The DeLone and McLean Model of Information Systems Success: A Ten Year Update. Journal of Management Information Systems, 19(4), 9-30.

Dewi, I. K., \& Zaky, A. (2020). Faktor-Faktor yang Mempengaruhi Penggunaan E- Learning Systems dalam Proses Belajar Mahasiswa Universitas Brawijaya. Jurnal Ilmiah Mahasiswa FEB Universitas Brawijaya, $7(2), 1-38$.

Doll, W. J., \& Torkzadeh, G. (1998). Developing A Multidimensional Measure of Systems Use In An Organizational Context. Information \& Management, 33(4), 171-185. https://doi.org/https://doi.org/10.1016/S037 8-7206(98)00028-7

Estriegana, R., Medina-Merodio, J. A., \& Barchino, R. (2019). Student acceptance of virtual laboratory and practical work. Computers and Education, 135, 1-14.

Feist, J., \& Gregory, J. (2006). Theories of Personality (Sixth). McGraw-Hill Companies.

Fornell, C., \& Larcker, D. . (1981). Evaluating Structural Equation Models with 
Unobservable Variables and Measurement Error. Journal of Marketing Research, 18(1), 39-50.

Hamdani. (2011). Strategi Belajar Mengajar. CV. Pustaka Seti.

Hernita, S. J., Sidik, W., \& Sanjaya, V. F. (2020). Pengaruh E-Service dan Kualitas Sistem terhadap Kepuasan Pengguna Sistem ELearning dengan Moderasi Perceived Value. Target: Jurnal Manajemen Dan Bisnis, 2(2), 257-264. https://journal.universitasbumigora.ac.id/in dex.php/target/article/view/1001

Isaac, O., Abdullah, Z., Ramayah, T., \& Mutahar, A. M. (2017). Examining the relationship between overall quality, user satisfaction and internet usage: an integrated individual, technological, organizaional and social perspective. Asian Journal of Information Technology, 16(1), 100-124.

Ithriah, S. A., Ridwandono, D., \& Suryanto, T. L. M. (2020). Online Learning Self-Efficacy: The Role in E-Learning Success. Journal of Physics: Conference Series, 1569(2). https://doi.org/10.1088/17426596/1569/2/022053

Jogiyanto. (2008). Analisis dan Desain Sistem Informasi: Pendekatan Terstruktur Teori dan Praktek Aplikasi Bisnis. Penerbit Andi.

Juliana, I. P., Utami, I. G. . L. P., \& Utami, I. A. M. I. (2021). Challenges in Operating University Moodle E-Learning: A Case Study From Lecturers' Perceptions. Jurnal Inovasi Dan Teknologi Pembelajaran, 8(1).

Kock, N. (2014). Advanced Mediating Effects Tests, Multi-group Analysis, and Measurement Model Assessments in PLS-based SEM. International Journal of E-Collaboration, 10(3), 1-13.

Kock, N. (2020). Warppls User manual: Version 7.0. ScriptWarp Systems: Laredo.

Kock, N., \& Lynn, G. S. (2012). Lateral Collinearity and Misleading Results in Variance-Based SEM: An Illustration and Recommendations. Journal of the Association for Information Systems, 13(7), 546-580.

Kurt, Ö. E. (2019). Examining an e-learning system through the lens of the information systems success model: Empirical evidence from Italy. Education and Information Technologies, 24(2), 1173-1184.

Lee-Post, A. (2009). E-Learning Success Model: An Information Systems Perspective. Electronic Journal of E-Learning, 7(1), 6170 .

Liaw, S.-S., \& Huang, H.-M. (2013). Perceived satisfaction, perceived usefulness and interactive learning environments as predictors to self-regulation in e-learning environments. Computers and Education, 60(1), 14-24.

Martins, J., Branco, F., Gonçalves, R., Au-YongOliveira, M., Oliveira, T., Naranjo-Zolotov, M., \& Cruz-Jesus, F. (2019). Assessing the success behind the use of education management information systems in higher education. Telematics and Informatics, 38, 182-193.

Maudiarti, S. (2018). Penerapan E-Learning Di Perguruan Tinggi. Perspektif Ilmu Pendidikan, 32(1), 51-66. https://doi.org/10.21009/pip.321.7

Nawaz, S. S. (2019). Effectiveness of LMS:Moodle Perspective fromSouth Eastern University of Sri Lanka. International Journal of Grid and Distributed Computing, 12(3), 172189.

Nunnally, J. C., \& Bernstein, I. H. (1994). Psychometric Theory. McGraw-Hill Companies.

Ong, C.-S., Day, M.-Y., \& Hsu, W.-L. (2009). A Measurement of User Satisfaction with Question Answering Systems. Information \& Management, 46(7), 397-403.

Ramirez-Correa, P. E., Rondan-Cataluna, F. J., Arenas-Gaitan, J., \& Alfaro-Perez, J. L. (2017). Moderating effect of learning styles on a learning management system's success. Telematics and Informatics, 34(1), 272286.

Safsouf, Y., Mansouri, K., \& Poirier, F. (2020). An analysis to understand the online learners' success in public higher education in Morocco. Journal of Information Technology Education: Research, 19, 87112.

Saied, H. (2017). The Impact of Simulation on Pediatric Nursing Students' Knowledge, Self-efficacy, Satisfaction, and Confidence. Journal of Education and Practice, 8(11).

Santoso, B., \& Legowo, N. (2015). Faktor-faktor Kesuksesan E-Learning dalam Meningkatkan Proses Belajar Mengajar di SMA Budi Mulia Karawang. Academia.

Schwieger, D., \& Ladwig, Ch. (2018). Reaching and Retaining the Next Generation: Adapting to the Expectations of Gen Z in the Classroom. Information Systems Education Journal, $16(3)$.

Seliana, N., Suroso, A. I., \& Yuliati, L. N. (2020). Analisis Keberhasilan Penerapan ELearning di Fakultas Teknik Universitas Riau. Jurnal Aplikasi Bisnis Dan Manajemen, $\quad 6(2), \quad 369-378$. https://doi.org/10.17358/jabm.6.2.369

Suganda, T. (2018). Pengelolaan Pembelajaran Generasi Z. Research Gate, 1-11.

Tafiardi. (2005). Meningkatkan Mutu Pendidikan Melalui E-Learning. Jurnal Pendidikan 
206 JINOTEP (Jurnal Inovasi dan Teknologi Pembelajaran) Kajian dan Riset dalam Teknologi Pembelajaran Vol.8, No.2, July 2021, Hal. 194-206

Penabur, 4(4), 85-97.

Wei, H.-C., \& Chou, C. (2020). Online learning performance and satisfaction: do perceptions and readiness matter? Distance Education, 41(1), 48-69.

Wood, R., \& Bandura, A. (1989). Impact of Conceptions of Ability on Self-Regulatory Mechanisms and Complex Decision Making. Journal of Personality and Social Psychology, 56(3), 407-415.
Yuliantoro, H. R. (2015). Analisis Faktor-Faktor uang Mempengaruhi Kepuasan Penggunaan Aplikasi E-Learning dengan Pelayanan Staf Pengajar sebagai Variabel Intervening. Seminar Nasional Teknologi Informasi Dan Komunikasi. Paper presented at Seminar Nasional Teknologi Informasi dan Komunikasi 2015 (SENTIKA 2015), Yogyakarta, 28 Maret 2015 (pp. 57-64). 